www.nature.com/ejhg

\title{
Autosomal dominant type lla hypercholesterolemia: evaluation of the respective contributions of LDLR and APOB gene defects as well as a third major group of defects
}

\author{
Bruno Saint-Jore ${ }^{1, *}$, Mathilde Varret ${ }^{1}$, Christiane Dachet ${ }^{1}$, Jean-Pierre Rabès ${ }^{1,2}$, \\ Martine Devillers ${ }^{1}$, Danielle Erlich ${ }^{3}$, Patricia Blanchard ${ }^{4}$, Michel Krempf $^{4}$, Denis Mathé ${ }^{5}$, \\ Bernard Chanu ${ }^{5}$, Bernard Jacotot ${ }^{5}$, Michel Farnier ${ }^{6}$, Catherine Bonaïti-Péllié ${ }^{7}$, \\ Claudine Junien $^{1,2}$ and Catherine Boileau ${ }^{1,2}$
}

\author{
${ }^{1}$ INSERM U383, Université Réné Descartes, Paris V, Hôpital Necker-Enfants Malades, Paris; ${ }^{2}$ Laboratoire de \\ Biochimie et de Génétique Moléculaire, CHU Ambroise Paré AP-HE, Boulogne; ${ }^{3}$ Service de Biochimie, \\ CHU Saint-Louis, Paris; ${ }^{4}$ Service d'Endocrinologie, CHU Hotel Dieu, Nantes; ${ }^{5}$ Service de M édecine Interne, \\ CHU Henry Mondor, Créteil; ' ${ }^{6}$ Point Médical, Dijon; ${ }^{7}$ IN SERM U351, Institut Gustave Roussy, Villejuif, France
}

\begin{abstract}
Autosomal dominant type lla hypercholesterolaemia (ADH) is characterised by an elevation of total plasma cholesterol associated with increased LDL particles. Numerous different molecular defects have been identified in the LDL receptor (LDLR) and few specific mutations in the apolipoprotein B (APOB) gene resulting in familial hypercholesterolaemia and familial defective apoB-100 respectively. To estimate the respective contribution of LDLR, APOB and other gene defects in this disease, we studied 33 well characterised French families diagnosed over at least three generations with ADH through the candidate gene approach. An estimation of the proportions performed with the HOMOG3R program showed that an LDLR gene defect was involved in approximately $50 \%$ of the families $(P=0.001)$. On the other hand, the estimated contribution of an APOB gene defect was only $15 \%$. This low estimation of ADH due to an APOB gene defect is further strengthened by the existence of only two probands carrying the APOB (R3500Q) mutation in the sample. More importantly and surprisingly, $35 \%$ of the families in the sample were estimated to be linked to neither LDLR nor APOB genes. These data were confirmed by the exclusion of both genes through direct haplotyping in three families. Our results demonstrate that the relative contributions of LDLR and APOB gene defects to the disease are very different. Furthermore, our results also show that genetic heterogeneity is, generally, underestimated in ADH, and that at least three major groups of defects are involved. At this point, the contribution of the recently mapped FH3 gene to ADH cannot be assessed nor its importance in the group of 'non LDLR / non APOB' families. European Journal of Human Genetics (2000) 8, 621-630.
\end{abstract}

Keywords: autosomal dominant typella hypercholesterolaemia; familial defective apolipoprotein B-100; familial hypercholesterolaemia; genetic heterogeneity; LDL receptor; apolipoprotein B

Correspondence: Professor C Boileau, INSERM U383, Hôpital

Necker-Enfants Malades, Clinique M Lamy, 149-161 Rue de Sèvres,

75743 Paris Cedex 15, France. Tel: +33 1444944 85;

Fax: + 331478332 06; E-mail: boileau@necker.fr

* Present address: INSERM U321, Hôpital Pitié-Salpétrière, Paris, France

Received 7 January 2000; revised 17 April 2000; accepted 27 April 2000 


\section{Introduction}

Typella hypercholesterol aemia is characterised

(1) biologically, by an elevated concentration of plasma cholesterol,

(2) clinically, by xanthomas, arcus corneae, and premature coronary heart disease, and

(3) genetically, usually by a dominant mode of inheritance. $^{1}$

The elevation of total cholesterol (TC) is due to an increase of cholesterol bound to low density lipoprotein particles (LDL), above the 95th percentile cut-off for the general population.

It was generally assumed that autosomal dominant hypercholesterolaemia (ADH) is exclusively due to a defect either in the LDLR (low density lipoprotein receptor) or the APOB (apolipoprotein B) gene. The term familial hypercholesterolemia $(\mathrm{FH})$ has been applied broadly to patients presenting with a mutation in the LDLR gene. This gene encodes a cell surface glycoprotein that mediates the removal from blood of cholesterol carrying LDL particles via apolipoprotein B. ${ }^{1,2}$ The LDLR gene in $19 p 13$ spans 45 kilobases and comprises 18 exons. ${ }^{3}$ Over 500 different mutations have been reported. ${ }^{4}$ However, individuals with elevated LDL cholesterol and normal LDL receptor activity have been reported as well as the absence of mutation in the LDLR gene of FH probands. ${ }^{5}$ Furthermore, no mutations are found after systematic sequencing of the LDLR gene in about $15 \%$ of probands. ${ }^{6,7}$ Among the latter, some probands probably do not carry a mutation in this gene. Thus FH does not account for all familial cases of high LDL cholesterol levels.

In hypercholesterolaemic patients, simultaneous measurement of turnover rates of autologous and normal homologous LDL demonstrated fractional clearance rates for autologous LDL that were significantly lower than those for normal homologous LDL. ${ }^{8}$ By in vitro binding studies, Innerarity et al ${ }^{9}$ demonstrated that in one case this reduced binding was the result of a defect in apolipoprotein B-100. Further studies of the APOB gene identified a single nucleotide substitution from $G \rightarrow A$, at nucleotide 10699, which resulted in a glutamine for an arginine substitution at residue 3500 (R3500Q). ${ }^{10}$ This molecular defect segregated in some families designated as presenting with familial defective apolipoprotein B-100 (FDB). This mutation was usually associated with the same haplotype, suggesting a common European ancestral mutation. ${ }^{11,12}$ Interestingly, a second hypercholesterolaemic mutation was described at the same codon resulting in a tryptophan for an arginine substitution APOB R3500W. ${ }^{13}$ Finally, Pullinger et al $^{14}$ reported a third mutation which decreases LDL binding activity: the APOB 3531 (R3531C) mutation at nucleotide10800, which results in a cysteine for an arginine substitution. However, in more recent studies, this mutation was not found associated with hypercholesterolaemia and/or coronary artery disease. ${ }^{15,16}$
These mutations are the only reported defects of the APOB gene associated with hypercholesterolaemia. Finally, we recently reported on the mapping of a third major gene named FH3 at chromosome1p34-p32, demonstrating the existence of further genetic heterogeneity for $\mathrm{ADH} .{ }^{17}$

The prevalence of monogenic hypercholesterolaemia in the general population has been determined on several occasions. Using the data from genetic analysis of hyperlipidaemia among consecutively studied survivors of myocardial infarction, Goldstein et al ${ }^{18}$ estimated a minimal heterozygote frequency for familial forms of isolated hypercholesterolaemia of 1 in 500 individuals of the general population. Subsequently, molecular defects in the LDLR gene were identified. It was generally assumed that these defects accounted for all the heterozygous forms of hypercholesterolaemia and therefore the $\mathrm{FH}$ heterozygote frequency was considered identical to that previously estimated for monogenic hypercholesterolaemia (ie 1/500). However, genetic heterogeneity was demonstrated through the identification of FDB whose prevalence was estimated between $1 / 500$ and $1 / 1000 .{ }^{19,20}$ Furthermore, as early as 1974 , Morganroth et $\mathrm{al}^{21}$ identified several probands presenting with 'pseudohomozygous typell hypercholesterolaemia' which is now known as 'familial recessive hypercholesterolaemia typeIV' (FH4). ${ }^{22}$ Probands with this autosomal recessive disease have normal LDL particles and LDL receptor activity, but a significant reduction in hepatic LDL uptake similar to that observed in $\mathrm{FH}$ homozygotes. Since phenotype of FH4 patients is strikingly identical to that of $\mathrm{FH}$ homozygous patients, it indicates the involvement of another group of defects. Finally, Hobbs et $\mathrm{al}^{23}$ clearly demonstrated that $\mathrm{a}$ mutation in the LDLR gene is not al ways associated with an $\mathrm{FH}$ clinical presentation because of the existence of 'compensatory' mechanisms. These observations show that monogenic typella hypercholesterolaemia is an heterogeneous group of disorders whose prevalence cannot be properly assessed through only clinical and biological data.

Several studies using various approaches (functional tests, ${ }^{7}$ molecular ${ }^{6,24}$ or genetic analyses ${ }^{25,26}$ ) have assessed the contribution of either LDLR or APOB gene defects to ADH. However, to our knowledge, no study has as yet been designed to simultaneously evaluate, and in a single sample, the respective contributions of FH and FDB to autosomal dominant typella hypercholesterolaemia. The need for these data has become important for diagnostic and research purposes since the recent localisation of the new FH 3 locus. ${ }^{17}$ To fill this gap, we used the candidate gene approach ${ }^{27}$ in a sample of French families. Segregation of ADH with polymorphic markers of the LDLR and APOB genes was studied in the families. Linkage analyses were performed and followed by computerised admixture tests:

i) HOMOG computes likelihoods under the hypothesis of two family types, one with linkage and the other one without linkage between the disease and the gene 
tested, and estimates the proportion of linked families; and

ii) HOMOG3R calculates likelihoods under the assumption that a disease is linked to genel (proportion $\alpha$ ) in some families, and to gene 2 (proportion $\beta$ ) in other families on another chromosome against the hypothesis that some families may be linked to an other unidentified gene (proportion $\gamma$ ) and estimates the three proportions

These tests allowed us to estimate, in our sample, the proportion of families with an LDLR $(\alpha)$ or an APOB $(\beta)$ gene defect. Furthermore, they al so demonstrated the existence of a third group of families $(\gamma)$ associated with mutations within one, or several, different locus (i).

\section{Materials and methods Probands and families}

Probands were ascertained among consecutive patients from lipid clinics belonging to four medical centres located either in the western or central parts of France or the Paris area. The following selection criteria were used: total and LDL cholesterol above the 95th percentile when compared with sex and age matched French populations, ${ }^{28}$ triglycerides below $1.3 \mathrm{mmol} / \mathrm{L}$, personal or documented familial xanthomas, and/or arcus corneae, and early coronary artery disease. Lipid measurements were repeated to ascertain the existence of primary typella hypercholesterolaemia. At the same time, family history and pedigrees were investigated. Forty-five probands matching the selection criteria and belonging to multiplex families displaying the disease over at least three generations were selected for the study. Family members were examined and their lipid levels repeatedly determined. Subsequently, only 36 families were selected ( 9 being eliminated because of existence of elevated triglyceride levels in some first-degree relatives, suggesting the possibility of familial combined hyperlipidaemia).

Genetic analyses using multi-allelic markers from different chromosomal regions led to the exclusion of three families for non-paternity. Finally, a total of 252 subjects from 33 hypercholesterolaemic families (with a mean of $2.3 \mathrm{sibs}$ and representing 172 meioses) was included in the study (Figure 1). Probands (mean age around 49 years old) had mean total cholesterol of $10.15 \pm 2.72 \mathrm{mmol} / \mathrm{L}$ and $7.29 \pm 2.01 \mathrm{mmol} / \mathrm{L}$, before and after hypocholesterolaemic treatment, respectively. Mean LDL cholesterol were $7.03 \pm 1.91 \mathrm{mmol} / \mathrm{L}$ and $5.58 \pm 2.01 \mathrm{mmol} / \mathrm{L}$, before and after treatment, respectively. Mean triglycerides was $1.01 \pm 0.29 \mathrm{mmol} / \mathrm{L}$. Phenotypic status for family members was initially established by the recruiting team on each site and was independently and blindly confirmed by members from other teams. A bimodal distribution was observed for the standardised total cholesterol values of all first-degree relatives. A bimodal distribution was also observed for raw
LDL-cholesterol values. Since this parameter is calculated and not directly measured, standardisation could not be performed. This explainsthestrong overlap observed in Figure2. Conversely, triglycerides values displayed an unimodal distribution similar to that of the normal population (data not shown). Finally arcus, corneae, myocardial infarction at early age, and xanthomas were variously observed among affected subjects in agreement with well documented variable expressivity in this disease.

\section{LDLR gene analysis}

Four biallelic polymorphisms of the LDLR gene were tested by PCR amplification: Taq1, BstEII, Hincll, and Avall located in introns 4 and 12 and in exons 12 and 13 respectively. ${ }^{25,29,30}$ Four multi-allelic markers were also tested, a polymorphism associated with an Alu sequence located within intron $15,{ }^{31}$ a $(C A)_{n}$ (D19S394), a (TAA) $n$ (D19S594) and a (TA $)_{n}$ repeat located respectively flanking, in intronic sequences and in the $3^{\prime}$ end of the LDLR gene. ${ }^{32,33}$ The Alu sequence was amplified by PCR on a 9600 Geneamp (Perkin-Elmer Biosystems, Courtaboeuf, France) for 30 cycles $\left(94^{\circ} \mathrm{C}\right.$ for $20 \mathrm{~s}$, $56^{\circ} \mathrm{C}$ for $20 \mathrm{~s}, 72^{\circ} \mathrm{C}$ for $30 \mathrm{~s}$ ) with $20 \mathrm{~mm}$ of each primer, $1 \mathrm{~mm}$ $\mathrm{MgCl}_{2}$, and radiolabelled $\alpha^{33} \mathrm{P}$ dATP. PCR products were migrated on a $5 \%$ non-denaturing polyacrylamide gel at $20 \mathrm{~V} / \mathrm{cm}$, and then the gel was dried and exposed overnight on to autoradiographic film (Kodak, Paris, France). For the diand tri-nucleotide repeats, two volumes of dye containing $95 \%$ formamide were added to each amplification product before electrophoresis on $10 \%$ denaturing polyacrylamide gels at $40 \mathrm{~V} / \mathrm{cm}$. DNAs were transferred to a Hybond $\mathrm{N}^{+}$ membrane (Amersham Pharmacia Biotech Europe, Orsay, France) and fixed in $\mathrm{NaOH} 0.4 \mathrm{M}$. Membranes were hybridised with $20 \mathrm{ng}$ of one of the PCR primers, radiolabelled by a $3^{\prime}$ tailing reaction (Boehringer, Mannheim, Germany), and incubated at $42^{\circ} \mathrm{C}$ for $3 \mathrm{~h}$ in phosphate buffer $0.13 \mathrm{M} \mathrm{pH}$, SDS 7\%, $\mathrm{NaCl} 0.5 \mathrm{~m}$ and PEG $10 \% .{ }^{34} \mathrm{M}$ embranes were washed and exposed to autoradiographic film for 4 to 10 hours. The $(\mathrm{TA})_{\mathrm{n}}$ repeat was originally described as a triallelic marker (7, 8 , and 10 repeats). However, we have identified two other alleles with 11 and 12 repeats.

\section{APOB gene analysis}

The multiallelic $3^{\prime} H V R^{11}$ and the $(T G)_{n}$ repeat $^{35}$ were PCR $^{2}$ amplified and their alleles were detected as described above. Running conditions for the 3'HVR marker were on a $4 \%$ denaturing acrylamide gel at $50 \mathrm{~V} / \mathrm{cm}$. An insertion/deletion polymorphism (SP) located in the signal peptide of the gene was PCR-amplified and run in an $8 \%$ non-denaturing polyacrylamide gel. ${ }^{36}$ Screening for the R3500Q and R3531C mutations in the APOB gene were performed by PCRmediated site-directed mutagenesis followed by $\mathrm{Mspl}$ and Mlul digestions. Two bands of smaller molecular weight were observed when either mutation was present. ${ }^{37}$ 

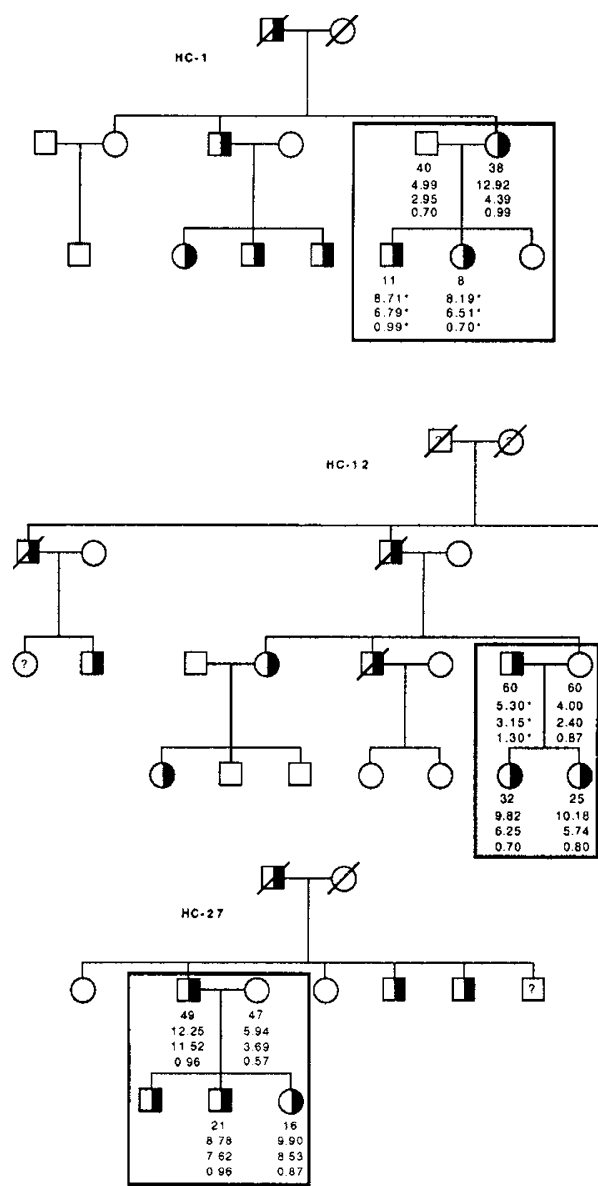

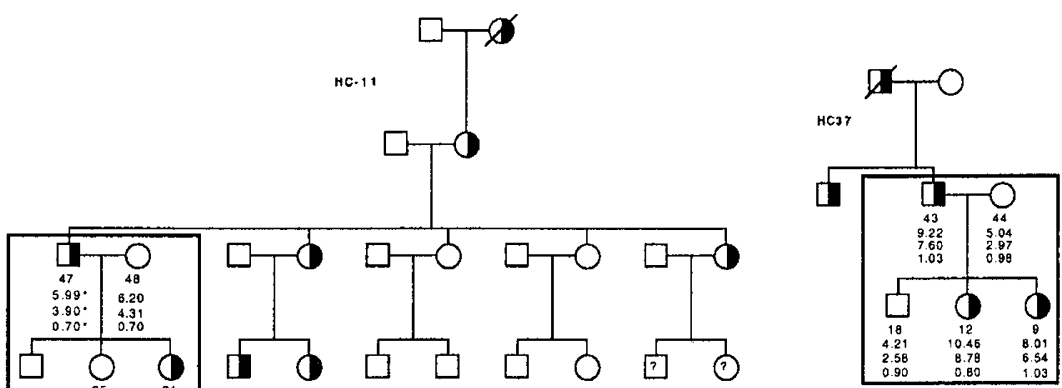

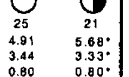
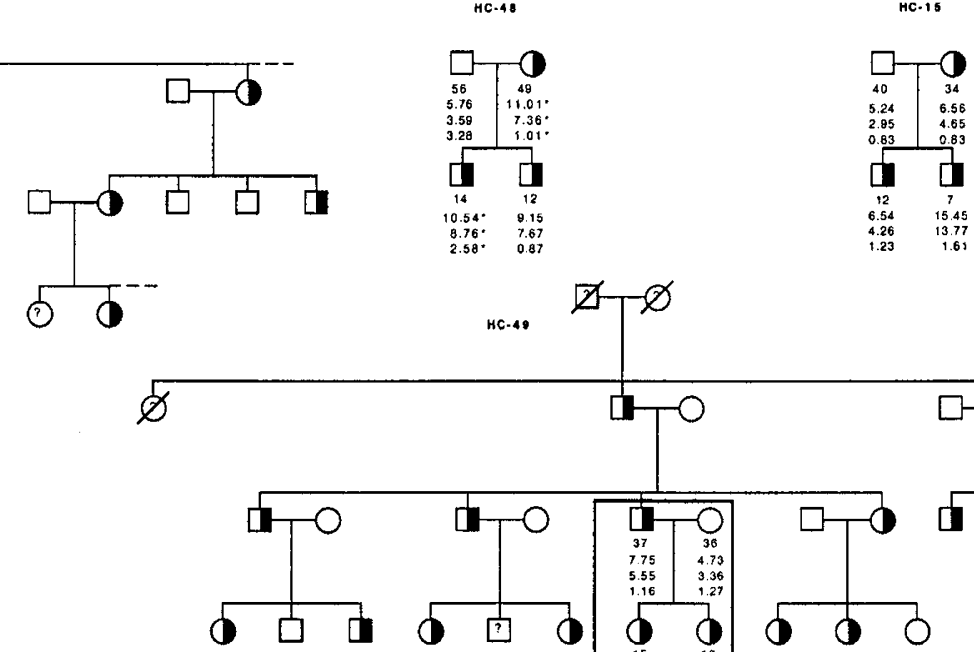

.
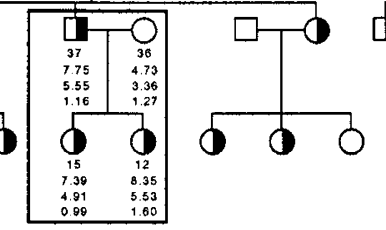

Figure 1 Pedigrees of eight out of $\mathbf{3 3}$ families showing autosomal dominant inheritance of the hypercholesterolaemic trait. Families used in the study are boxed. Half-filled symbols denote affected individuals, open symbols denote unaffected members, open symbols with a question mark represent individuals with unknown status. Under each patient's symbol are listed: age at lipid measurement, total cholesterol, LDL-cholesterol, and triglycerides. Asterisks describe values obtained after hypocholesterolaemic treatment and diet. All lipid values are expressed in $\mathrm{mmol} / \mathrm{L}$.

\section{Genetic studies}

Pairwise lod scores were computed at 8 recombination fraction $(\Theta=0.001,0.005,0.01,0.02,0.03,0.04,0.05$, and 0.10$)$ using the MLINK subprogram of the LINKAGE package (version 5.1). ${ }^{38}$ Lod score analyses were performed with a complete or incomplete penetrance ( 1.0 or 0.9 , respectively) for heterozygous individuals. The admixture estimation test $^{39}$ was performed using two HOMOG programs: HOMOG and HOMOG 3 R. ${ }^{40}$ HOMOG computes likelihoods under the hypothesis of two family types, one with linkage and the other one without linkage to the locus tested and estimates the proportion of linked families. HOMOG3R calculates likelihoods under the assumption that a trait is linked to locus 1 (proportion $\alpha$ ) in some families, and to locus 2 (proportion $\beta$ ) in other families on another chromosome, against the hypothesis that some families may be linked to another unidentified locus (proportion $\gamma$ ) and estimates the three proportions. We used this program HOMOG3R, where both loci are candidate genes and with lod scores evaluated at $\Theta=0.001$.

Linkage homogeneity was also tested between families sampled in the Paris area and various centres from the western part of France. We used the following property of the maximum likelihood ratio test. When a given sample is divided into $k$ subsamples, if $L_{t}$ is the maximum likelihood for the whole sample and $L_{i}$ the maximum likelihood for subsample $\mathrm{i}$, then $-2 \mathrm{Ln}\left(\mathrm{L}_{\mathrm{t}} / \Sigma_{\mathrm{i}} \mathrm{L}_{\mathrm{i}}\right)$ asymptotically follows a $\chi^{2}$ distribution with $n(k-1)$ degrees of freedom, where $n$ is the number of estimated independent parameters. In our case, the estimated parameters were $\alpha$ and $\beta$ since thetas were set at 0.001 .

\section{Results}

Genetic analysis for the LDLR and APOB genes

Molecular defects responsible for ADH have been identified in two genes: LDLR and APOB. To estimate their respective 


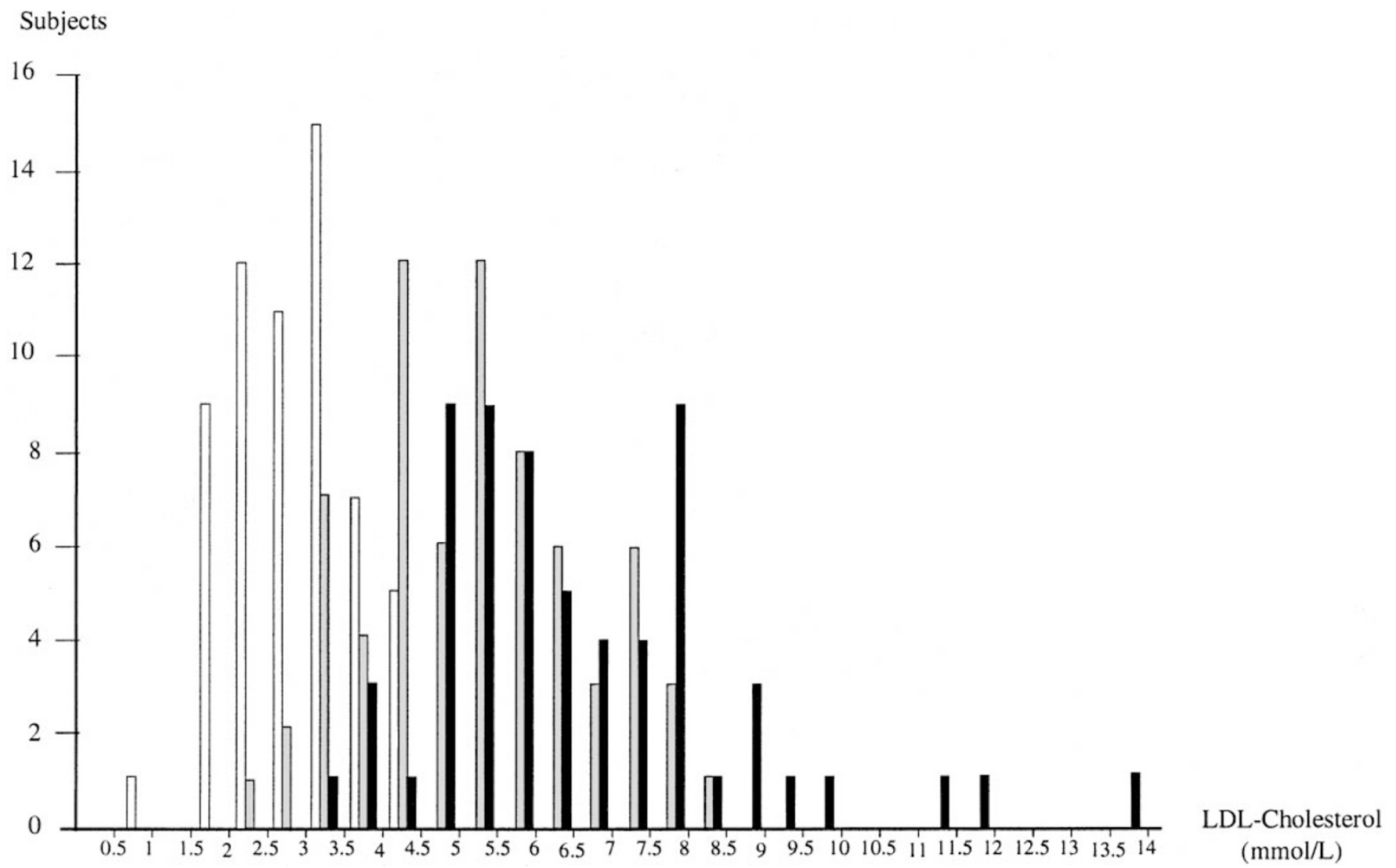

Figure 2 Distribution of LDL cholesterol values. Bars represent the number of first degree relatives per category; open bars represent non-affected subjects, grey bars affected individuals with treatment and/or diet for whom detailed lipid values prior to treatment were not available, and black bars affected individuals prior to treatment.

contribution to the disease, we recruited 33 families (252 individuals) with a compatible autosomal dominant transmission of this trait over three generations (Figure1). To evaluate the families linked to either LDLR or APOB genes, individuals were first haplotyped using polymorphic LDLR and APOB gene markers, respectively. Then a classic genetic linkage analysis was performed using the MLINK program. Because of the small size of many of the families, mostly exclusions could be definitively ascertained.

For the LDLR gene markers, linkage disequilibrium between different polymorphic markers considerably reduced the overall informativity at this locus. Therefore we increased the number of polymorphic markers tested to eight, resulting in 30 informative families out of 33 (Table1):

1) linkage (lod score $\geq 2.00$ under the candidate gene approach) was reached in $\mathrm{HC} 5$ family;

2) an exclusion (lod score $\leq-2.00$ ) could be definitely demonstrated in $23 \%$ (7/30) of the informativefamilies (HC2, 6, 13, 32, 33, 47, and 70);

3) 20 families displayed small positive lod scores; and
4) two families displayed small negative lod scores

These two groups included both linked and unlinked families but because of the size of the families the exclusion or linkage threshold could not be reached.

5) only three families remained non-informative (lod score $=0.00$ ) because probands were homozygous for all tested markers ( $\mathrm{HC} 3,31$, and 36$)$.

These results showed that at least $23 \%$ of the ADH families of the sample were not carrying an LDLR gene defect.

For the APOB locus, 30 families were informative (Table1):

1) an exclusion was definitely demonstrated in $43 \%$ $(13 / 30)$ of the informative families;

2) 17 families displayed low positive or negative lod scores;

3) only three families remained non-informative

These results showed that, in this population, an important fraction of $\mathrm{ADH}(43 \%)$ is not due to a defect in the APOB gene. In addition, we looked for the FDB mutations at amino 
Table 1 Multipoint lod scores between familial type lla hypercholesterolaemia and LDLR and APOB gene markers at $\theta=0.001$ in 33 families investigated performed under complete and 0.9 penetrance

\begin{tabular}{|c|c|c|c|c|c|c|c|}
\hline \multirow[b]{2}{*}{ Family } & \multirow{2}{*}{$\begin{array}{l}\text { Total number } \\
\text { of subjects } \\
(n=252)\end{array}$} & \multirow{2}{*}{$\begin{array}{l}\text { Affected } \\
\text { subjects } \\
(n=117)\end{array}$} & \multirow{2}{*}{$\begin{array}{l}\text { Number of } \\
\text { meioses } \\
(n=172)\end{array}$} & \multicolumn{2}{|c|}{$\begin{array}{c}\text { Lod scores at } \\
\text { penetrance: } 1.0\end{array}$} & \multicolumn{2}{|c|}{$\begin{array}{c}\text { Lod scores at } \\
\text { penetrance: } 0.9\end{array}$} \\
\hline & & & & LDLR & APOB & LDLR & APOB \\
\hline $\mathrm{HCl}$ & 4 & 3 & 2 & 0.30 & 0.30 & 0.30 & 0.30 \\
\hline $\mathrm{HC} 2$ & 38 & 6 & 29 & -4.25 & -3.82 & -2.43 & -1.89 \\
\hline $\mathrm{HC} 3$ & 5 & 2 & 3 & 0.00 & 0.60 & 0.00 & 0.52 \\
\hline $\mathrm{HC} 5$ & 15 & 6 & 12 & 2.23 & -2.34 & 2.09 & -2.34 \\
\hline HC6 & 43 & 11 & 32 & -17.62 & -9.59 & -5.34 & -4.22 \\
\hline HC8 & 5 & 4 & 3 & 0.30 & -1.86 & 0.30 & -1.78 \\
\hline $\mathrm{HC} 11$ & 4 & 2 & 2 & 0.30 & 0.30 & 0.26 & 0.26 \\
\hline $\mathrm{HC} 12$ & 4 & 3 & 2 & 0.30 & -2.05 & 0.30 & -1.97 \\
\hline $\mathrm{HCl} 3$ & 6 & 3 & 4 & -2.40 & -2.10 & -1.43 & -0.18 \\
\hline $\mathrm{HCl} 4$ & 11 & 7 & 14 & 1.75 & -5.86 & 1.71 & -3.30 \\
\hline HC15 & 4 & 3 & 2 & 0.30 & 0.00 & 0.30 & 0.00 \\
\hline HC19 & 4 & 2 & 2 & 0.30 & -2.40 & 0.26 & -0.73 \\
\hline HC2O & 7 & 4 & 5 & 0.36 & -2.05 & 0.32 & -2.00 \\
\hline $\mathrm{HC} 23$ & 6 & 2 & 4 & 0.30 & 0.30 & 0.26 & 0.26 \\
\hline $\mathrm{HC} 24$ & 5 & 3 & 3 & 0.30 & 0.60 & 0.30 & 0.56 \\
\hline HC30 & 4 & 2 & 2 & 0.30 & -2.40 & 0.26 & -0.73 \\
\hline HC31 & 4 & 2 & 2 & 0.00 & 0.30 & 0.00 & 0.26 \\
\hline HC32 & 4 & 3 & 2 & -2.05 & 0.00 & -1.98 & 0.00 \\
\hline HC33 & 4 & 3 & 2 & -2.05 & 0.30 & -1.98 & 0.30 \\
\hline HC34 & 5 & 3 & 3 & 0.30 & -2.05 & 0.30 & -1.98 \\
\hline HC35 & 5 & 4 & 3 & -1.86 & -1.86 & -1.78 & -1.79 \\
\hline HC36 & 4 & 2 & 2 & 0.00 & -2.40 & 0.00 & -0.73 \\
\hline HC37 & 5 & 3 & 3 & 0.60 & -2.40 & 0.56 & -0.44 \\
\hline HC38 & 4 & 3 & 2 & 0.30 & 0.30 & 0.30 & 0.30 \\
\hline HC42 & 6 & 5 & 5 & 0.86 & 0.73 & 0.86 & 0.73 \\
\hline HC43 & 5 & 4 & 3 & 0.60 & 0.46 & 0.60 & 0.46 \\
\hline HC44 & 5 & 2 & 3 & -0.21 & -0.65 & -0.10 & -0.44 \\
\hline HC45 & 4 & 2 & 2 & 0.30 & 0.30 & 0.26 & 0.26 \\
\hline HC47 & 5 & 3 & 3 & -2.40 & 0.00 & -2.29 & 0.00 \\
\hline HC48 & 4 & 3 & 2 & 0.30 & -2.05 & 0.30 & -1.97 \\
\hline HC49 & 4 & 3 & 2 & 0.30 & 0.30 & 0.30 & 0.30 \\
\hline $\mathrm{HC} 70$ & 15 & 6 & 10 & -5.01 & 1.50 & -3.18 & 1.45 \\
\hline
\end{tabular}

acids R3500Q and R3531C in all probands and their spouses, by PCR-mediated site-directed mutagenesis analysis. In the HC24 and HC70 families, probands and several affected members were found positive for the APOB (R3500Q) mutation (data not shown). This direct analysis showed that APOB contribution was at least of $6 \%(2 / 33)$.

Importantly, when combined together these results underscored the existence of a third group of families that showed an exclusion for both genes $(\mathrm{HC} 2, \mathrm{HC} 6$, and $\mathrm{HC} 13$, see below). Thus, when considering only the sub-sample of families in which informativity was obtained at both loci, $11 \%(3 / 27)$ of families are unlinked to either locus.

\section{Estimation of the proportions of families associated with LDLR, APOB or 'non-LDLR, non-APOB' gene defects} To estimate the proportion of families linked to either of the candidate genes, we used the HOMOG computer package that analyses the likelihoods computed with the MLINK program. Different analyses were performed using either the LDLR or the APOB gene markers alone (HOMOG), and using both LDLR and APOB gene markers and testing for the evidence of a third family type (HOMOG3R). We did these analyses with different parameters corresponding to different models. Under the first hypothesis, penetrance was considered complete assuming that every individual carrying a mutation was hypercholesterolaemic. In the second model the penetrance was rated at 0.9 for heterozygotes. This second model was investigated to take into account the observed overlap of the distributions of cholesterol levels between affected and unaffected subjects in our sample and also reported by other groups, ${ }^{1}$ as well as the single report of incomplete penetrance in a large $\mathrm{FH}$ family. ${ }^{23}$

The HOMOG tests were highly significant and unsurprisingly confirmed the existence of genetic heterogeneity in the sample. However, they estimated the proportion of families linked to LDLR gene defects at $\alpha=54 \%$ and APOB gene defects were estimated $\beta=23 \%$ and $20 \%$ according to the two different models (penetrance $=1.0$ and 0.9 , respectively) (Table2). These results confirmed that familial typella hypercholesterolaemia was heterogeneous since LDLR and APOB gene mutations were already identified. However, the contribution of the LDLR locus was much higher than that of the APOB locus. These results also showed that defects in the LDLR and the APOB genes did not account for all cases of 
Table 2 Results of HOMOG analyses for the LDLR and APOB genes

\begin{tabular}{lll}
\hline & LDLR & APOB \\
\hline & $\alpha=54 \%$ & $\beta=23 \%$ \\
Penetrance 1.0 & $(23-79)^{*}$ & $(0-54)^{*}$ \\
& $Z_{\max }(\Theta)=5.18(0.001)$ & $Z_{\max }(\Theta)=0.89(0.005)$ \\
& $P=0.0001$ & $P=0.021$ \\
& $\alpha=54 \%$ & \\
Penetrance 0.9 & $(23-80)^{*}$ & $\beta=20 \%$ \\
& $Z_{\max }(\Theta)=4.87(0.001)$ & $(0-49)^{*}$ \\
& $P=0.002$ & $Z_{\max }(\Theta)=0.87(0.005)$ \\
\end{tabular}

*confidence interval

ADH in our sample. Since the HOMOG program performs its statistical analysis testing the existence of linkage between the trait and a single locus, the proportion $\gamma$ of 'non LDLR/ non APOB' families is more adequately estimated by using the HOM OG3R sub-program which tests for linkage between the trait and two distinct loci under the candidate gene hypothesis. This test confirmed the values obtained previously for the LDLR gene with $\alpha=(50 \%)$ and slightly reduced the contribution $\beta$ of the APOB gene to $15 \%$. More importantly, it estimated at $35 \%$ the proportion $(\gamma)$ of families linked neither to the LDLR nor the APOB genes. Identical proportions were obtained whatever the model used and both tests were highly significant $(P=0.0001)$.

Since these families originated from two different geographical areas, we tested the homogeneity of our populations by a linkage homogeneity test between samples. The predivided sample test was applied, using the maximum likelihood values obtained for each family sub-sample with the HOMOG3R program. The test showed no statistically significant difference between the 13 families sampled in Paris and the 19 from the other French centres $\left(\chi_{2}^{2}=1.14\right.$, $P<0.50)$.

\section{Identification of three 'non-LDLR / non-APOB' families}

As the contribution of 'non-LDLR / non-APOB' families was estimated at $35 \%$, we sought to distinctly identify families that would definitively demonstrate the involvement of a third locus. A careful analysis of segregation of markers in our sample disclosed the presence of three families in whom exclusion of the two candidate genes LDLR and APOB could be demonstrated (HC2, HC6 and HC13) (Figure3). In family $\mathrm{HC}$, at the LDLR locus the affected proband transmitted the same allele $(H 2, A 1, T 3)$ to her affected and non-affected sons. At the APOB locus, the proband also transmitted the same allele $(T 3, S 2, V 7)$ to her two sons. A similar analysis performed for family $\mathrm{HC} 6$ demonstrates the existence of another non-LDLR / non-APOB family (Figure3). Furthermore, these data were supported by cellular and molecular analyses. Genetic exclusions observed for the LDLR gene were confirmed by in vitro studies showing that LDL receptor activity in the probands from both families was equal to that of a normal control subject (data not shown). For the APOB gene, genetic exclusion was confirmed by absence of two APOB R3500Q and R3531C mutations. Finally, genotyping of members at large in the two families identified further recombinants among affected and unaffected subjects and confirmed the exclusion data for both candidate genes (data not shown). In the case of family $\mathrm{HC13}$, samples could not be obtained from affected individuals to evaluate LDL receptor activity.

\section{Discussion}

The aim of this study was to evaluate the respective contributions ofLDLR, APOB and other gene defects to dominant typella hypercholesterolaemia using genetic linkage analysis and homogen eity tests for linkage in a sample of French families. The families investigated were ascertained through probands that were identified among consecutive patients from the four centres over a period of 2 years. Only nuclear families were studied and, whenever possible, multiplex families were sampled and explored. The exclusion criteria used for the probands were in agreement with generally accepted criteria ${ }^{41}$ and rather conservative, since families with subjects presenting triglycerides levels superior to $1.3 \mathrm{mmol} / \mathrm{L}$ were excluded. An overlap of the distribution is observed with LDL-cholesterol values (Figure2). This is due to the unavailability of published reference values of LDLcholesterol. However, when considering the age of the subjects, their status can be unequivocally ascertained.

Results from the HOMOG analyses showed the existence of gen etic heterogeneity in the sample. In effect, the hypothesis for linkage heterogeneity ( $\mathrm{H} 2 \mathrm{Vs} \mathrm{H} 1$ ) was significant for the LDLR and APOB genes (Table2). The tests also showed that LDL receptor defects were by far the most common in our sample of ADH families since they were estimated to account for $54 \%$ of the cases. Conversely, the contribution of the APOB gene defects was estimated at only $20-30 \%$. There is a discrepancy between these figures and the identification of only two families ( $\mathrm{HC} 24$ and $\mathrm{HC} 70$ ) who carry the APOB R3500Q mutation. Therefore, the contribution of this mutation was estimated at only $6 \%$ in the sample of ADH families. This is in agreement with other European populations as reported by Tybjærg-Hansen et $\mathrm{al}^{42}{ }^{42} \mathrm{Talmud}$ et al, ${ }^{43} \mathrm{Miserez}$ et $\mathrm{al}^{44}$ and Rabès et al. ${ }^{37}$ The discrepancy can be explained by the rather large confidence interval associated with the results of the HOMOG tests for the APOB gene markers (Table2). However, since the genetic approach we used analyses the possible involvement of a candidate gene and not of a single mutation, our sample could contain a few families carrying still unidentified hypercholesterolaemic mutations of the APOB gene.

Careful observation of APOB and LDLR gene haplotypes as well as linkage data revealed that in three families ( $\mathrm{HC2}$, $\mathrm{HC} 6$, and $\mathrm{HC} 13$ ) the defect was linked to neither of the candidate genes. Therefore to estimate the proportion $\gamma$ of 'non-LDLR/non-APOB' families, we used a more adequate 
LDLR

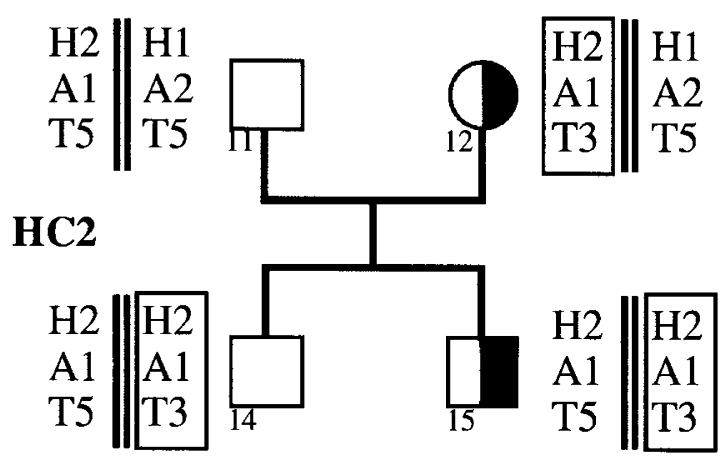

APOB

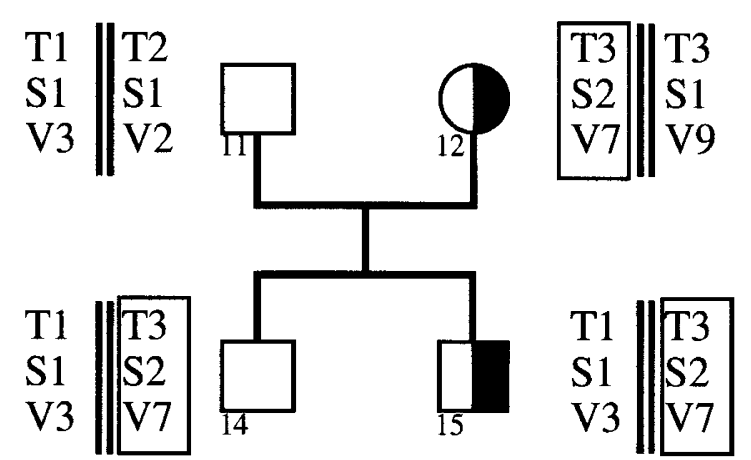

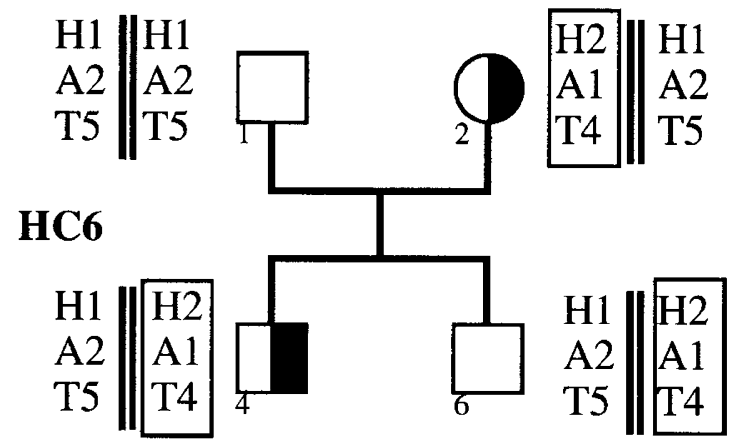
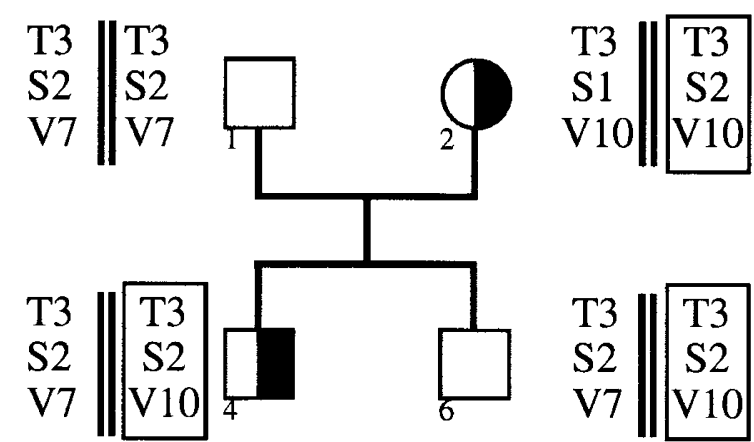

Figure 3 Exclusion of the LDLR and APOB gene markers in two hypercholesterolaemic families HC2 and HC6. Haplotypes for each family member are shown in the following order: LDLR gene haplotypes [H: Hincll, A: Avall, T: (TA) n)], APOB gene haplotypes [T: $\left.(T G)_{n}, \mathrm{~S}: \mathrm{SP}, \mathrm{V}: 3^{\prime} H V R\right]$. 1: Absence of the polymorphic site or presence of the insertion. 2: Presence of the polymorphic site or of the deletion. TG 1, 2, $3 \leftrightarrow 15,14,13$ repeats, respectively. TA 3, 4, $5 \leftrightarrow 10,8,7$ repeats, respectively. 3'HVR: 12 alleles have been identified in our laboratory. They are numbered from 1 to 12 according to their molecular weight. Allele no. 2 has 48 repeats and is often associated with the APOB R3500Q mutation. In each family haplotypes of interest are boxed.

program: HOM OG3R. It tests for heterogeneity using simultaneously linkage data obtained with markers from the two candidate genes. The tests were highly significant and clearly demonstrated the existence of greater genetic heterogeneity. The new estimated proportions for LDLR and APOB genes were at $55 \%$ and $15 \%$, respectively, not statistically different from the estimations previously obtained with the HOMOG tests. LDLR gene defects were still the most common cause of $\mathrm{ADH}$ despite the tested hypothesis of existence of three loci associated with the disease. The test confirmed the low contribution of APOB gene defects. Finally, it also showed that $\gamma$ accounted for $35 \%$ of the mutations in our sample, thus second to LDLR gene defects.

The results of the genetic analyses were confirmed in two families (HC2 and HC6) by the LDL receptor assay which was normal for both probands (data not shown). Ultracentrifugation analyses of HC2 and HC6 probands' plasma showed a typical typella profile with an elevation of LDL particles similar to the pattern observed for patients with an LDLR mutation (data not shown). The clinical and biological findings in these families are identical to those of other typella families, but are in general mild and therefore closer to FDB than $\mathrm{FH}^{17}$ At the present stage, the identity of the third locus is unknown, but we proved that $\gamma$ represents a gen etically heterogeneous class of defects. In effect, through a genome-wide search, we mapped at 1p34-p32 the disease locus for $\mathrm{HC} 2$ and called it ' $\mathrm{FH} 3$ ' ${ }^{17}$ Because of the size of the region on chromosome $1(8-9 \mathrm{cM})$, it is impossibleto perform admixture tests using anonymous loci markers to evaluate the proportion of families liked to the FH3 locus. However, linkage was excluded between $\mathrm{FH} 3$ and the disease in $\mathrm{HC} 6$ family. Taken together these results clearly demonstrate that there are at least four loci involved in ADH and that $\gamma$ is a heterogeneous class of molecular defect. However, because of the numerous proteins, enzymes and receptors involved in cholesterol homeostasis, it is not surprising that there are 
several 'non-LDLR / non-APOB' loci involved in $A D H$. Identification of these loci will probably unravel new pathogenic mechanisms responsible for hypercholesterolaemia and associated with coronary artery disease. It may also lead to the development of new cholesterol-lowering agents.

In conclusion our results obtained in a sample of $33 \mathrm{ADH}$ families show that

1) mutations in the LDLR gene are the most frequent defects;

2) molecular defects associated with the disease are located within at least four loci;

3) together the unknown loci, have a greater contribution to the phenotype than that of the APOB gene.

These results obtained in a small sample of French families await confirmation in other populations and better assessment in larger samples, but do not preclude the identification of the gene involved in the three French 'non-LDLR / nonAPOB' ADH families reported.

\section{Acknowledgements}

The authors wish to thank Maria Martinez for numerous fruitful and helpful discussions. This work was supported by INSERM, Faculté de M édecine N ecker, Université Paris V, PROGRES-INSERM, ARCOL, and Parke-Davis.

\section{References}

1 Goldstein J, Brown M: Familial Hypercholesterolemia. In: Scriver C, Beaudet A, Sly W, Valle D (eds): The M etabolic Basis of Inherited Disease, 6th edn. McGraw-Hill: New York, 1989, pp 1215-1250.

2 Yamamoto T, Davis CG, Brown MSet al: The human LDL receptor: a cysteine-rich protein with multiple Alu sequences in its mRNA. Cell 1984; 39: 27-38.

3 Lindgren V, Luskey KL, Russell DW, Francke U: Human genes involved in cholesterol metabolism: chromosomal mapping of the loci for the low density lipoprotein receptor and 3-hydroxy3-methylglutaryl-coenzyme A reductase with cDNA probes. Proc Natl Acad Sci USA 1985; 82: 8567-8571.

4 Varret M, Rabes JP, Thiart R et al: LDLR Database, 2nd edn. New additions to the database and the software, and results of the first molecular analysis Nucleic Acids Res 1998; 26: 248-252.

5 McKusick V: Mendelian Inheritance in Man. John Hopkins University Press: Baltimore, 1988.

6 Hobbs HH, Brown MS, Goldstein JL: Molecular genetics of the LDL receptor gene in familial hypercholesterolemia. Hum Mutat 1992; 1: 445-466.

7 Sun XM, Patel DD, Knight BL, Soutar AK: Comparison of the genetic defect with LDL-receptor activity in cultured cells from patients with a clinical diagnosis of heterozygous familial hypercholesterolemia. The Familial Hypercholesterolaemia Regression Study Group. Arterioscler Thromb Vasc Biol 1997; 17: 3092-3101.

8 Vega GL, Grundy SM: In vivo evidence for reduced binding of low density lipoproteins to receptors as a cause of primary moderate hypercholesterolemia. J Clin Invest 1986; 78: 1410-1414.

9 Innerarity $\mathrm{TL}$, Weisgraber $\mathrm{KH}$, Arnold KS et al: Familial defective apolipoprotein B-100: low density lipoproteins with abnormal receptor binding. Proc Natl Acad Sci USA 1987; 84: 6919-6923.

10 Soria LF, Ludwig EH, Clarke HR, Vega GL, Grundy SM, McCarthy $\mathrm{BJ}$ : Association between a specific apolipoprotein B mutation and familial defective apolipoprotein B-100. Proc Natl Acad Sci USA 1989; 86: 587-591.
11 Ludwig EH, McCarthy BJ: Haplotype analysis of the human apolipoprotein B mutation associated with familial defective apolipoprotein B100. Am J Hum Genet 1990; 47: 712-720.

12 Loux N, Saint-Jore B, Collod G et al: Identification of the haplotype associated with the APOB-3500 mutation in a French hypercholesterolemic subject: further support for a unique European ancestral mutation. Hum Mutat 1993; 2: 145-147.

13 Gaffney D, Reid JM, Cameron IM et al: Independent mutations at codon 3500 of the apolipoprotein $B$ gene are associated with hyperlipidemia. Arterioscler Thromb Vasc Biol 1995; 15: 1025-1029.

14 Pullinger CR, Hennessy LK, Chatterton JE et al: Familial liganddefective apolipoprotein $\mathrm{B}$. Identification of a new mutation that decreases LDL receptor binding affinity. J Clin Invest 1995; 95: 1225-1234.

15 Ludwig EH, Hopkins PN, Allen A et al: Association of genetic variations in apolipoprotein B with hypercholesterolemia, coronary artery disease, and receptor binding of low density lipoproteins. J Lipid Res 1997; 38: 1361-1373.

16 Tybjærg-Hansen A, Steffensen R, Meinertz H, Schnohr P, Nordestgaard BG: Association of mutations in the apolipoprotein $B$ gene with hypercholesterolemia and the risk of ischemic heart disease. N Engl J Med 1998; 338: 1577-1584.

17 Varret M, Rabès JP, Saint-Jore B et al: A third major locus for autosomal dominant hypercholesterolemia maps to 1p34.1-p32. Am J Hum Genet 1999; 64: 1378-1387.

18 Goldstein JL, Schrott HG, Hazzard WR, Bierman EL, Motulsky AG: Hyperlipidemia in coronary heart disease. II. Genetic analysis of lipid levels in 176 families and delineation of a new inherited disorder, combined hyperlipidemia. J Clin Invest 1973; 52: 1544-1568.

19 Innerarity TL, Mahley RW, Weisgraber $\mathrm{KH}$ et al: Familial defective apolipoprotein B-100: a mutation of apolipoprotein B that causes hypercholesterolemia. J Lipid Res 1990; 31: 1337-1349.

20 Rauh G, Keller C, Schuster H, Wolfram G, Zollner N: Familial defective apolipoprotein B-100: a common cause of primary hypercholesterolemia. Clin Invest 1992; 70: 77-84.

21 Morganroth J, Levy RI, M cMahon AE, Gotto AM Jr: Pseudohomozygous typell hyperlipoproteinemia. J Pediatr 1974; 85: 639-643.

22 Zuliani G, Arca M, Signore A et al: Characterization of a new form of inherited hypercholesterolemia: familial recessive hypercholesterolemia. Arterioscler Thromb Vasc Biol 1999; 19: 802-809.

23 Hobbs HH, Leitersdorf E, Leffert CC, Cryer DR, Brown MS, Goldstein JL: Evidence for a dominant gene that suppresses hypercholesterolemia in a family with defective low density lipoprotein receptors. J Clin Invest 1989; 84: 656-664.

24 Nissen $\mathrm{H}$, Hansen PS, Faergeman $\mathrm{O}$, Horder $\mathrm{M}$ : Mutation screening of the codon 3500 region of the apolipoprotein $B$ gene by denaturing gradient-gel electrophoresis. Clin Chem 1995; 41: 419-423.

25 Miserez AR, Schuster H, Chiodetti N, Keller U: Polymorphic haplotypes and recombination rates at the LDL receptor gene locus in subjects with and without familial hypercholesterolemia who are from different populations. Am J Hum Genet 1993; 52: 808-826.

26 Haddad L, Day IN, Hunt S, Williams RR, Humphries SE, Hopkins PN: Evidence for a third genetic locus causing familial hypercholesterolemia. A non-LDLR, non-APOB kindred. J Lipid Res 1999; 40: 1113-1122.

27 Lusis AJ: Genetic factors affecting blood lipoproteins: the candidate gene approach. J Lipid Res 1988; 29: 397-429.

28 Steinmetz J: Le Cholestérol total. In: Siest G, Henny J, Schiele F (eds): Références en Biologie Clinique. Elsevier: Paris, 1990, pp 190-209.

29 Leitersdorf E, Tobin EJ, Davignon J, Hobbs HH: Common lowdensity lipoprotein receptor mutations in the French Canadian population. J Clin Invest 1990; 85: 1014-1023. 
30 Loux N, Saint-Jore B, Collod G et al: Screening for new mutations in the LDL receptor gene in seven French familial hypercholesterolemia families by the single strand conformation polymorphism method. Hum Mutat 1992; 1: 325-332.

31 Orita M, Sekiya T, Hayashi K: DNA sequence polymorphisms in Alu repeats. Genomics 1990; 8: 271-278.

32 Ashworth LK, Batzer MA, Brandriff B et al: An integrated metric physical map of human chromosome19. Nat Genet 1995; 11: 422-427.

33 Zuliana G, Hobbs HH: Dinucleotide repeat polymorphism at the $3^{\prime}$ end of the LDL receptor gene. Nucleic Acids Res 1990; 18: 4300.

34 Hazan J, Dubay C, Pankowiak MP, Becuwe N, Weissenbach J: A genetic linkage map of human chromosome20 composed entirely of microsatellite markers. Genomics 1992; 12: 183-189.

35 Boerwinkle E, Xiong WJ, Fourest E, Chan L: Rapid typing of tandemly repeated hypervariable loci by the polymerase chain reaction: application to the apolipoprotein $B 3^{\prime}$ hypervariable region. Proc Natl Acad Sci USA 1989; 86: 212-216.

36 Boerwinkle E, Chan L: A three codon insertion/deletion polymorphism in the signal peptide region of the human apolipoprotein $B(A P O B)$ gene directly typed by the polymerase chain reaction. Nucleic Acids Res 1989; 17: 4003.

37 Rabès JP, Varret $M$, Saint-Jore $B$ et al: Familial ligand-defective apolipoprotein B-100: simultaneous detection of the ARG $3500 \rightarrow$ GLN and ARG3531 $\rightarrow$ CYS mutations in a French population. Hum Mutat 1997; 10: 160-163.
38 Lathrop GM, Lalouel JM, Julier C, Ott J: Strategies for multilocus linkage analysis in humans. Proc Natl Acad Sci USA 1984; 81: 3443-3446.

39 Smith C: Testing for heterogeneity of recombination values in human genetics. Am J Hum Genet 1963; 27: 175-182.

$40 \mathrm{Ott}$ J: Analysis of Human Genetic Linkage. Johns Hopkins University Press: Baltimore, 1991.

41 Williams RR, Hunt SC, Schumacher MC et al: Diagnosing heterozygous familial hypercholesterolemia using new practical criteria validated by molecular genetics. Am J Cardiol 1993; 72: 171-176.

42 Tybjærg-Hansen A, Gallager J, Vincent J et al: Familial defective apolipoprotein B-100: detection in the United Kingdom and Scandinavia, and clinical characteristics of ten cases. Atherosclerosis 1990; 80: 235-242.

43 Talmud P, Tybjærg-Hansen A, Bhatnagar D et al: Rapid screening for specific mutations in patients with a clinical diagnosis of familial hypercholesterolaemia. Atherosclerosis 1991; 89: 137-141.

44 Miserez AR, Laager R, Chiodetti N, Keller U: High prevalence of familial defective apolipoprotein B-100 in Switzerland. J Lipid Res 1994; 35: 574-583. 